\title{
The neuroprotective effect of long-term n-3 polyunsaturated fatty acids supplementation in the cerebral cortex and hippocampus of aging rats
}

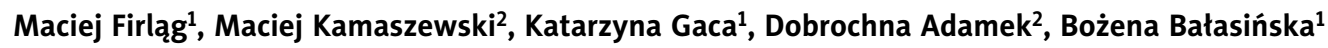 \\ ${ }^{1}$ Department of Physiological Science, Faculty of Veterinary Medicine, SGGW, ${ }^{2}$ Department of Ichthyobiology and Fisheries, \\ Faculty of Animal Science, SGGW, Warsaw, Poland
}

\begin{abstract}
The purpose of this study was to determine whether hippocampus and cerebral cortex fatty acids (FA) composition can be altered as a result of $n-3$ enriched diet, or modifications in $F A$ can affect the age-related histological changes in these brain tissues. The study was performed on eighteen rats which were fed control (CD) or fish oil supplemented diet (FOD) for 12 months. We investigated the $n-3$ and $n-6$ brain FA profile by gas-chromatography analysis. Histomorphometry included the measurement of the quantity of pyramidal cells in the cerebral cortex (layer II-III) and in the hippocampal formation (CA1, CA3 and DG). The number of apoptotic cells (neuron and glial cells) was also calculated separately in three hippocampal areas and in the pyramidal cerebral cortex layer. Rats fed supplemented diet showed a significantly poorer content of the arachidonic acid (AA, 20:4n6) in all brain regions when compared to the control group. Furthermore, the level of the docosahexaenoic acid (DHA, 22:6n3) was significantly higher in the cerebral cortex in fish oil fed rats vs. the control group. The neurons of the pyramidal cortex showed significant changes in cell density in control animals when compared to the group of fish oil fed rats. Furthermore, the number of positive apoptotic cells was significantly higher in the CA1 area and cerebral pyramidal layer in rats fed control diet. Following dietary n-3 fatty acids supplementation, the increase in DHA content in the cerebral cortex resulted in consequential changes in histology of this tissue. The results obtained indicate that dietary intake of fish $n-3$ fatty acids may reduce the risk of age-related brain impairments.
\end{abstract}

Key words: brain, aging, docosahexaenoic acid, arachidonic acid, n-3 PUFA, apoptosis.

\section{Introduction}

The average human lifespan shows a continued increase [18]. This is the reason for growing interest in the identification of changes and diseases accompanying the process of aging in the brain [21]. Humans are unique among mammals as they are susceptible to certain neuropathologies such as Alzheimer's disease $(A D)$ or Parkinson disease in the later stages of their life. Even in the absence of neuropathological diseases, aging in humans is marked by variable degrees of neuronal deterioration and cognitive impairment. Diffuse amyloid- $\beta$ deposits, dendritic attrition, reduced synapse numbers, loss of 
NMDA receptors (N-methyl-D-aspartate; a type of ionotropic glutamate receptor), and degeneration of myelinated axons have all been observed to preferentially affect regions of the human cerebral cortex that are involved in learning, memory and executive function $[13,24]$. The same changes also accompany normal senescence in other species and correlate with the distruption of cognition [6,24]. Invariably, any description or characterization of brain aging includes a histological description of the hippocampus and cerebral cortex [18]. The hippocampus is located in the middle of the brain, and it plays a role in many brain functions, such as learning, memory, analysis of knowledge, cognition, and communication [11]. Hippocampus is a complex structure divided into separate but interconnected anatomic subregions: the entorhinal cortex, the dentate gyrus (DG), the CA subfields, and the subiculum. Each hippocampal subregion contains a distinct population of neurons that express a unique molecular profile. This uniqueness can account for differences in susceptibility to mechanisms of memory dysfunction [25]. The CA1 part of hippocampus is one of the initial brain areas displaying pathology and neuronal loss in AD [18]. Similarly, the grey matter of the cerebral cortex is a convoluted sheet of the tissue and is divided into several cells layers. The importance of the cerebral cortex has drawn scientists' attention to the study of its age-related modifications in the last few decades. In the cortex cerebri, particular subsets of pyramidal cells are prone to degradation, whereas others are not. The pyramidal cells that furnish long corticocortical projections are thought to be particularly vulnerable to degeneration in $A D$, leading to a global distruption of interconnections between association cortices, whereas primary sensory and motor areas exhibit a minimal neuron loss. Thus, although degenaration in AD is extensive, it is selective, and given the broad array of circuits that degenerate, it is not surprising that multiple domains of cognition are disrupted, including memory and attention [19].

One of the main metabolic functions of dietary n-3 polyunsaturated fatty acids (PUFA) is to support DHA accretion in phospholipid membranes and to ensure proper brain development, because the $n-3$ PUFA are critical contributors to the cell structure and function in the nervous system. A deficit in dietary DHA appears to contribute to inflammatory signalling, apoptosis, and neuronal dysfunction and is associated with a cognitive decline at the old age and age-related neurological disorders [3]. Age-related metabolic changes as well as the increase in the oxidative stress results in a lower concentration of n-3 PUFA in the nervous system [27]. Dietary DHA supplementation resulted in normalization of the age-related decrease in cognitive functions stimulating the production of new polyunsaturated phosphatidylserine species in the brain cerebral cortex and hippocampus [3]. Hence, n-3 PUFA are recommended for patients with mild AD or $\mathrm{MCl}$ (mild cognitive dysfunction), which also points out to a preventive effect rather than a potential treatment modality [8].

It is widely known that dietary intake of n-3 FA may decrease the functional and structural disorders resulting from aging. We assumed that the longterm feeding of fish oil can have significant effects of supplementation. For this purpose, we used Salmon oil as a source of n-3 FA and fed the experimental rat group for 12 consecutive months. Therefore, the aim of this study was to establish the FA composition in brain of old rats and to examine several possible histological implications with age-related changes in the cerebral cortex and hippocampus as well as to find corelations between FA content and these changes.

\section{Material and methods}

This protocol has been evaluated and approved by the Animal and Ethics Review Committee at the Warsaw Life Science University, Poland.

\section{Animals and diets}

Six-week-old male Sprague-Dawley rats obtained from Charles River Laboratories were acclimated for 2 weeks. Before the experiments all rats had ad libitum access to control diet and tap water to adjust to their new environment. Animals were housed in individual cages, under controlled temperature $\left(22^{\circ} \mathrm{C}\right)$ and humidity $(70 \%)$ and with $12: 12$ lightdark cycle. Eighteen rats were randomly assigned to 2 experimental groups $(2 \times 9)$ and fed for 12 months either control (CD) or experimental diet (FOD). The semi-synthetic, isoenergetic diet was prepared in our laboratory. The diets were based on nutritionally balanced formulation, and contained $10 \%$ fat (Table I). Fats used for the preparation of chow derived from lard, rapeseed oil and from Salmon (Salmonidae) which 
was the major source of n-3 PUFA (Tables II and III). Body weight and food intake were measured once a week. After 12 months, rats were euthanized by intraperitoneal injection of sodium pentobarbital. Cerebral cortex and hippocampus were dissected from the brain. Isolated brain samples were divided into two parts (left and right). Left brain samples were used for biochemical analysis, the other samples for histology. These for immunohistochemistry and histomorphometry were fixed in $4 \%$ formaldehyde in phosphate-buffered saline, dehydrated with ethanol and xylene, and embedded in paraffin. The brain for biochemical analysis was frozen in liquid nitrogen and stored at $-80^{\circ} \mathrm{C}$ until analysis.

\section{Lipid extraction and methylation}

Lipids were extracted in accordance with Folch method [12]. Briefly, the sample (for diet $-1 \mathrm{~g}$, for brain - $200 \mathrm{mg}$ ) was extracted with a chloroform-methanol (2:1) mixture. Brain samples were previously homogenized (pulped) in porcelain mortar with some Silicic acid (Mallinckrodt, 2847). After extraction, the chloroform layer was evaporated with a stream of $\mathrm{N}_{2}$. The sample was then saponified with $1 \mathrm{ml}$ of $3 \mathrm{M} \mathrm{KOH}$ in $\mathrm{MeOH}$ at $80^{\circ} \mathrm{C}$ for $35 \mathrm{~min}$, then cooled and hexane extracted. After evaporation residue was dissolved in $3 \mathrm{ml}$ of distilled water and $100 \mu \mathrm{l}$ of $4 \mathrm{M} \mathrm{HCl}$ to obtain $\mathrm{pH} \sim 2$. Next, $3 \mathrm{ml}$ of hexane was added to extract
Table I. Composition of the diets

\begin{tabular}{|lcc|}
\hline Ingredient (\%) & CD & FOD \\
\hline Protein & & \\
\hline Casein & 20.00 & 20.00 \\
\hline Carbohydrate & 1.00 & 1.00 \\
\hline Potato starch & 48.20 & 48.20 \\
\hline Wats & & \\
\hline Rapeat starch & 1.00 & 2.00 \\
\hline Salmon oil & 0.00 & 6.00 \\
\hline Lard & 9.00 & 2.00 \\
\hline Additives & & \\
\hline Mineral mix ${ }^{1}$ & 3.68 & 3.68 \\
\hline Vitamin mix ${ }^{2}$ & 1.00 & 1.00 \\
\hline L-Methioninine & 0.22 & 0.22 \\
\hline Fluids & 15.90 & 15.90 \\
\hline Water & & \\
\hline
\end{tabular}

$C D$ - control diet, FOD - fish oil diet

${ }^{1}$ Composition of Macro-mineral mixture [ $\mathrm{g} / \mathrm{kg}$ of diet]: $\mathrm{CaHPO}_{4} \times 2 \mathrm{H}_{2} \mathrm{O}, 27.89$; $\mathrm{K}_{2} \mathrm{HPO}_{4}$ 2.43; $\mathrm{NaCl}, 0.92 ; \mathrm{K}_{2} \mathrm{SO}_{4}$ 2.04; $\mathrm{CaCO}_{3}$ 0.63; $\mathrm{Na}_{2} \mathrm{HPO}_{4} \times 12 \mathrm{H}_{2} \mathrm{O}, 1.61$; $\mathrm{MgO}, 0.75$. Composition of Micro-mineral mixture $\left[\mathrm{g} / 100 \mathrm{~g}\right.$ of diet]: $\mathrm{C}_{3} \mathrm{H}_{4}(\mathrm{OH})$ (COO) $3 \mathrm{Fe} \times 3 \mathrm{H}_{2} \mathrm{O}, 37.85 ; \mathrm{Zn}\left(\mathrm{CH}_{3} \mathrm{COOH}\right)_{2} \times 2 \mathrm{H}_{2} \mathrm{O}, 7.88 ; \mathrm{MnCO}_{3}, 23.41 ; \mathrm{Cu}(\mathrm{CH}-$ $\left.{ }_{3} \mathrm{COOH}\right)_{2} \times \mathrm{H}_{2} \mathrm{O}, 4.95 ; \mathrm{KJ}, 0.04 ; \mathrm{C}_{3} \mathrm{H}_{4}(\mathrm{OH})(\mathrm{COOH})_{3}$, complemented to $100 \mathrm{~g}$. ${ }^{2}$ Composition of vitamin mixture [ $\mathrm{g} / \mathrm{kg}$ of diet]: Vitamin A, 0.0069; Vitamin $\mathrm{D}_{3}$, 0.005 ; Vitamin E, 0.982; PABA, 1; Inositol, 1; Niacin, 0.4; D-calcium pantothenate, 0.4; Vitamin $B_{2}, 0.08$; Vitamin $B_{1}, 0.05$; Vitamin $B_{6}, 0.05$; Folic acid, 0.02; Biotin 0.004; Vitamin $B_{12}, 0.0003$; Choline, 20; Wheat starch, Comlemented to $100 \mathrm{~g}$.

Table II. Fatty acid composition of the treatment fats

\begin{tabular}{|lccc|}
\hline FA (\% of total FA) & Salmon oil & Lard & Rapeseed oil \\
\hline$\Sigma$ SFA & $47.56 \pm 7.24$ & $69.65 \pm 11.75$ & $30.58 \pm 3.26$ \\
\hline$\Sigma$ MUFA & $22.31 \pm 2.75$ & $21.03 \pm 6.53$ & $10.74 \pm 2.12$ \\
\hline C18:2n6 (trans-LA) & nd & nd & $22.32 \pm 0.40$ \\
\hline C18:2n6 (cis-LA) & $4.63 \pm 0.17$ & $6.98 \pm 0.03$ & $18.14 \pm 0.15$ \\
\hline C20:3n6 & $0.18 \pm 0.01$ & $0.29 \pm 0.17$ & $0.25 \pm 0.01$ \\
\hline C20:4n6 (AA) & $1.75 \pm 0.01$ & $n d$ & $0.63 \pm 0.04$ \\
\hline C22:4n6 & nd & nd & nd \\
\hline C22:5n6 & $0.51 \pm 0.16$ & $7.28 \pm 2.82$ & $n d$ \\
\hline$\Sigma(n-6)$ PUFA & $7.08 \pm 1.81$ & $1.24 \pm 0.47$ & $17.35 \pm 10.42$ \\
\hline C18:3n3 (ALA) & $4.65 \pm 0.19$ & nd & nd \\
\hline C20:5n3 (EPA) & $11.18 \pm 0.23$ & nd & nd \\
\hline C22:5n3 & $1.50 \pm 0.12$ & nd & nd \\
\hline C22:6n3 (DHA) & $4.50 \pm 0.12$ & $1.24 \pm 0.62$ & $17.28 \pm 8.64$ \\
\hline$\Sigma(n-3)$ PUFA & $21.84 \pm 4.08$ & \\
\hline
\end{tabular}

Values are mean $\pm S D$

SFA - saturated fatty acids, MUFA - monounsaturated fatty acids, PUFA - polyunsaturated fatty acids, nd - not detected. 
Table III. Fatty acid composition of the treatment diets

\begin{tabular}{|lcc|}
\hline FA (\% of total FA) & CD & FOD \\
\hline$\Sigma$ SFA & $63.35 \pm 11.37$ & $46.61 \pm 6.40$ \\
\hline$\Sigma$ MUFA & $23.75 \pm 5.72$ & $18.86 \pm 1.88$ \\
\hline C18:2n6 (trans-LA) & $2.64 \pm 0.05$ & $3.45 \pm 0.25$ \\
\hline C18:2n6 (cis-LA) & $8.60 \pm 0.20$ & $13.2 \pm 0.01$ \\
\hline C20:3n6 & $0.28 \pm 0.09$ & $0.57 \pm 0.04$ \\
\hline C20:4n6 (AA) & $n d$ & $0.66 \pm 0.01$ \\
\hline C22:4n6 & $n d$ & $0.10 \pm 0.01$ \\
\hline C22:5n6 & $n d$ & $0.26 \pm 0.01$ \\
\hline$\Sigma(n-6)$ PUFA & $11.52 \pm 3.43$ & $18.25 \pm 5.12$ \\
\hline C18:3n3 (ALA) & $1.01 \pm 0.01$ & $8.20 \pm 0.14$ \\
\hline C20:5n3 (EPA) & $n d$ & $3.29 \pm 0.01$ \\
\hline C22:5n3 & nd & $0.14 \pm 0.01$ \\
\hline C22:6n3 (DHA) & nd & $3.81 \pm 0.07$ \\
\hline$\Sigma(n-3)$ PUFA & $1.01 \pm 0.50$ & $15.44 \pm 3.31$ \\
\hline
\end{tabular}

Values are mean $\pm S D$

$C D$ - control diet, FOD - fish oil diet, SFA - saturated fatty acids, MUFA monounsaturated fatty acids, PUFA - polyunsaturated fatty acids, nd - not detected.

fatty acids. The upper, hexane layer was transferred to another tube, evaporated and methylated with $1 \mathrm{~mL} \mathrm{HCl}$ in $\mathrm{MeOH}$ for $35 \mathrm{~min}$ at $85^{\circ} \mathrm{C}$. The fatty acid methyl ester (FAME) sample exposed to a stream of $\mathrm{N}_{2}$ was stored in PTFE lined screw-capped vials and briefly analysed using GC.

\section{Gas chromatography analysis}

FAME was separated on $100 \mathrm{~m} \times 0.25 \mathrm{~mm}$ I.D. $\times 0.2 \mu \mathrm{m}$ CP-Sil 88 column, gas chromatograph equipped with autosampler and FID detector. The column temperature was kept at $170^{\circ} \mathrm{C}$ for the first $42 \mathrm{~min}$, raised to $240^{\circ} \mathrm{C}$ at the rate of $5^{\circ} \mathrm{C} / \mathrm{min}$, and maintained at this temperature for $31 \mathrm{~min}$. Identification of peaks corresponding to FAME was accomplished by means of a standard mixture of 37 FAMEs. The relative concentration of individual fatty acids was expressed as a percent of total fatty acids.

\section{Histomorphometry}

Samples of brain embedded in paraffin blocks were cut into $5 \mu \mathrm{m}$ thick sections using a Leica RM 2265 microtome (Leica Microsystems, Nussloch, Germany) at the level of frontal cortex $(3.24 . .1 .92 \mathrm{~mm}$ from Bregma) and hippocampus (-2.28..-5.20 mm from Bregma). The sections were stained with hematoxylin and eosin (HE) using standard methodology for histomorphometric examinations. The neuronal counts were determined using magnification $400 \times$. Histomorphometry consisted of the measurements of (a) pyramidal cells density of II-III layer in the cerebral cortex, which were measured in 30 areas of $1 \mathrm{~mm}^{2}$, (b) density in the hippocampal CA1, CA3 and dentate gyrus (DG) regions, which were measured in 5 areas of $1 \mathrm{~mm}^{2}$ in each sample. The measurements were performed based on images taken by a digital camera (NICON DS5-U1) attached to a NICON ECLIPSE 90i microscope and the computer image analysis system NIS-Elements AR (NICON Corporation, Tokyo, Japan).

\section{Immunohistochemistry}

Immunohistochemical examination was conducted on the same individual rats, which were subjected to histomorphometry. The protein p53 accumulation in aging rats was detected with monoclonal mouse antibody anti-p53 (DO-7) (Ventana Medical Systems/Roche Diagnostics Ltd, 05278775001) following manufacturer's recommendations. One dispenser $(5 \mathrm{ml})$ for 50 tests contains approximately $0.5 \mu \mathrm{g} / \mathrm{ml}$ of mouse monoclonal antibody (DO-7). The antibody was diluted in PBS and contained carrier protein and preservative. Staining was performed with Benchmark instrument using ultraView DAB Universal Detection Kit (Ventana Medical Systems/Roche Diagnostics Ltd, 05269806001). The procedures for staining on the Ventana automated slide stainers are as follows: deparaffinization (washing in xylene baths, ethanol gradient and deionized water), cell conditioning (antigen unmasking), antibody applying, counterstaining with hematoxylin and post counterstaining. In general, immunohistochemical staining allowed for the visualization of antigens via the sequential application of a specific antibody (primary antibody) to the antigen, a secondary antibody (link antibody) to the primary antibody, an enzyme complex and a chromogenic substrate with interposed washing steps. The enzymatic activation of the chromogen results in a visible reaction product at the antigen site. The slides were counterstained and cover slipped. Results were interpreted using a light microscope in a similar fashion to the histomorphometric measurements. The number of apoptotic cells (neuron and glial cells) was counted separately in three hippocampal areas 
(CA1, CA3 and DG) and in the pyramidal cell layer (II-III) in the cerebral cortex. Hippocampal formation was measured in 5 areas, the pyramidal cell layer was measured in 10 areas of $1 \mathrm{~mm}^{2}$.

\section{Statistical analysis}

Data are presented as mean \pm SD. Distribution of the groups was analyzed with Kolmogorov-Smirnov test. A $p$-value $<0.05$ was considered to be significant.

\section{Results}

As shown in Table IV, the supplementation of FOD with n-3 PUFA did not change the weight of the rats. There was also no variation in the brain weights between the two dietary groups. The profile of brain FA reflected the composition of ingested dietary fats (Table V). As a result of diet fortified with fish oil, the content of AA significantly decreased in all brain regions when compared to the control group. In the hippocampus, the AA concentration was reduced by $16 \%$ and in the cerebral cortex by $17 \%$, whereas total n-6 PUFA accumulation was lower by $27 \%$ and $18 \%$, respectively. The concentration of EPA was not detected. The level of DHA was significantly higher in the cerebral cortex in experimental rats (21.6\%) in comparison to the control group (19.3\%). In the hippocampus, there were no significant differences between the two dietary groups. The total amount of $\mathrm{n}-3$ PUFA in the hippocampus of the supplemented group slightly increased by $9 \%$, while in the cerebral cortex by $11 \%$ as compared to the control groups.

Histological measurements are presented in Fig. 1. There was no significant difference in the number of pyramidal neurons in the hippocampus and in DG between fish oil feed rats and the control group.
Table IV. Body and tissue rat weight at 14 month

\begin{tabular}{|lcc|}
\hline Tissue $(\mathrm{g})$ & $\mathrm{CD}$ & FOD \\
\hline Initial body weight & $100 \pm 30$ & $100 \pm 30$ \\
\hline Final body weight & $728.90 \pm 98.60$ & $730.50 \pm 94.55$ \\
\hline Brain & $2.10 \pm 0.11$ & $2.09 \pm 0.20$ \\
\hline Hippocampus & $0.12 \pm 0.02$ & $0.12 \pm 0.02$ \\
\hline Cerebral cortex & $0.66 \pm 0.08$ & $0.66 \pm 0.05$ \\
\hline
\end{tabular}

Values are mean $\pm S D$

$C D$ - control diet, FOD - fish oil diet

On average, 11.02 (CD), 11.17 (FOD) cells $/ \mathrm{mm}^{2}$ were counted in DG of the granular layer and 6.98 (CD), 6.62 (FOD) in CA1 and 4.87 (CD), 4.63 (FOD) cells/ $\mathrm{mm}^{2}$ in $\mathrm{CA} 3$ of the pyramidal layer. On the contrary, the pyramidal cortex neurons showed an important increase by $24 \%$ in neuron density in rats fed supplemented diets $\left(1.92\right.$ cells $/ \mathrm{mm}^{2}$ ) versus rats from control diet (1.47 cells $/ \mathrm{mm}^{2}$ ).

Using the anti-p53 clone DO-7 antibody we found only a very occasional neuron weak immunolabeling. Stronger staining was found in the glial cells. The results of apoptotic cell calculations in the cerebral cortex, hippocampus proper (CA1, CA3) and DG are summarized in Table VI. The number of apoptotic cells was significantly higher in CA1 (6.86 cells $/ \mathrm{mm}^{2}$ ) and cortex $\left(11.33\right.$ cells $\left./ \mathrm{mm}^{2}\right)$ of rats' brain in the control group. On the other hand, the number of apoptotic neurons from supplemented rats decreased significantly by $20 \%$ in the cortex and by $32 \%$ in CA1 when compared to the control group.

\section{Discussion}

In the present study, we examined the effects of long-term (12 months) diet supplemented in Salmon

Table V. Concentration of n-3 and n-6 fatty acid in hippocampus and cerebral cortex at 14 months old rats

\begin{tabular}{|ccccc|}
\hline FA (\% of total FA) & \multicolumn{2}{c}{ Hippocampus } & \multicolumn{2}{c|}{ Cerebral cortex } \\
\cline { 2 - 5 } & CD & FOD & CD & FOD \\
\hline$\Sigma(n-6)$ PUFA & $14.5 \pm 0.12$ & $10.5 \pm 0.21$ & $13.2 \pm 0.15$ & $10.8 \pm 0.27$ \\
\hline C20:4n-6 (AA) & $10.4 \pm 0.24^{\mathrm{a}}$ & $8.7 \pm 0.27^{\mathrm{b}}$ & $9.6 \pm 0.4^{\mathrm{a}}$ & $7.9 \pm 0.58^{\mathrm{b}}$ \\
\hline$\Sigma(\mathrm{n}-3)$ PUFA & $12.4 \pm 0.03$ & $13.7 \pm 0.49$ & $19.3 \pm 0.43$ & $21.7 \pm 0.16$ \\
\hline C22:6n-3 (DHA) & $12.3 \pm 0.06$ & $13.4 \pm 0.85$ & $19.3 \pm 0.75^{\mathrm{a}}$ & $21.6 \pm 0.29^{\mathrm{b}}$ \\
\hline AA/DHA & $0.8 \pm 0.02$ & $0.6 \pm 0.03$ & $0.5 \pm 0.06$ & $0.4 \pm 0.05$ \\
\hline
\end{tabular}




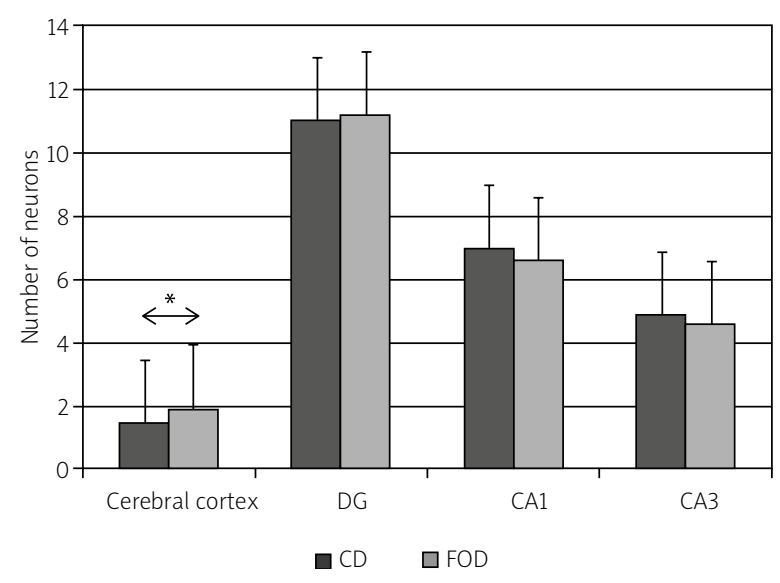

Fig. 1. Number of pyramidal neurons (cell $/ \mathrm{mm}^{2}$ ) in hippocampus proper (CA1, CA3) as well as cerebral cortex and granule cells in dentate gyrus (DG). Results are presented as mean \pm SD.

oil (rich in n-3 FA) on the DHA and AA concentration in two brain regions and whether it caused histological changes in the brain of rats. We prepared an experimental diet containing 3.81\% DHA and 3.29\% EPA and evaluated the results of feeding this diet in 14-month-old rats. In addition to differing PUFA concentration, the control and experimental diet differed in their saturated and monounsaturated FA (Table III). Feeding rats the fish oil diet (FOD) reduced the levels of AA in the hippocampus $(-16 \%)$ and cerebral cortex $(-17 \%)$ when compared to animals from the control group (CD). This was probably due to the competition between $n-6$ and $n-3$ for the desaturation systems. Both the n- 6 and n-3 FA pathways are believed to utilize the same desaturase enzymes, and desaturation is subject to competitive substrate and product inhibition [26]. Thus, desaturation leading to AA can be inhibited by dietary EPA and DHA. Igarashi et al. [15]

Table VI. Apoptotic cell counts (cell/ $/ \mathrm{mm}^{2}$ ) in cortex and hippocampus of rat diet groups

\begin{tabular}{|lccc|}
\hline Tissue & & CD & FOD \\
\hline Cerebral cortex & & $11.33 \pm 1.20^{\mathrm{a}}$ & $9.00 \pm 0.09^{\mathrm{b}}$ \\
\hline $\begin{array}{l}\text { Hippocampal } \\
\text { formation }\end{array}$ & DG & $5.20 \pm 2.90$ & $3.86 \pm 0.75$ \\
\cline { 2 - 4 } & CA1 & $6.86 \pm 0.98^{\mathrm{a}}$ & $4.66 \pm 1.89^{\mathrm{b}}$ \\
\cline { 2 - 4 } & CA3 & $5.27 \pm 2.20$ & $4.38 \pm 0.91$ \\
\hline
\end{tabular}

Values are mean $\pm S D$

$C D$ - control diet, FOD - fish oil diet, $a, b$ - significantly different between groups, $p<0.05$ used an n-6 PUFA deficient diet and compared it with an adequate control diet. Their study showed that $A A$ concentration was reduced in total serum lipids, and to a various degree in other tissues, i.e. brain, liver, heart, testis and adipose tissue. The authors imply that different percent reductions may be related to differences in AA turnover rats and/or stable lipid concentrations among the organs and lead to different organ functional changes.

A significantly higher concentration of DHA has been found in the cerebral cortex (21.6\%) in rats fed FOD when compared to the control group. Thus, the cerebral cortex which contains a higher level of DHA was more effective in DHA accumulation and less resistant to fluctuations in FA composition from diet. In the hippocampus, no effect of FOD was observed on DHA levels. Results of the present study show a lower bioavailability of the DHA in face of n-3 FA supply for the hippocampus than the cerebral cortex. In this case, the biological effects of dietary FA may affect the OXPHOS (oxidative phosphorylation) pathway. In the hippocampal area CA1, several OXPHOS genes encoding subunits of complexes involved in the electron transport chain and of the critical enzyme F1F0 ATP synthase were upregulated in rats supplemented with DHA. Generally, these data suggest that high n-3 dietary intakes favour mitochondrial ATP production and activity of the electron transport complexes in the brain [14]. This may be connected with the fact that PUFA are more vulnerable to free radical oxidation which increases with age. This indicates that a decrease in PUFAs concentration in hippocampus may increase the chances of survival of aged neurons through a reduction in the generation of toxic products. On the other hand, DHA is the major component of brain membrane phospholipids (maintain an appropriate state of fluidity) and is necessary for preservation of neuronal functions $[5,10]$. A significant age-dependent decrease was observed in the levels and turnover of the PUFAs in the hippocampus, cortex, striatum and hypothalamus. Several mechanisms have been proposed to explain this reduction: a low rate of penetration of PUFAs from blood into the brain under oxidative stress, altered FA metabolism, enzymatic and non-enzymatic peroxidation and altered levels of the enzymes desaturase. Considering these data, supplementation with n-3 FA appears to be justified.

Our findings also present the correlation between the content of FA and their effects on the histology 
of the brain. The results obtained revealed that the increase in concentration of DHA results in positive alternations at the cellular level of the tissue. Our study demonstrates that n-3 FA supplemented diet leads to an increase in the number of pyramidal neurons in the cerebral cortex by $24 \%$. In this case, $n-3$ fortified diet probably promotes neurite growth and synaptogenesis. It is generally accepted that more synaptic connections can be made with longer neurites and a higher number of dendritic branches. Additionally, synaptic activity in developing neurons further promotes dendritic arbour elaboration and stabilizes dendritic structure, which is critical for synaptic remodelling during memory [9]. The hippocampus did not reach statistical significance in neurons density. This could be due to the lack of changes in the concentration of DHA in the tissue. Ahmad et al. [1] have shown that rats fed deficient (as compared to the enriched with n-3 FA) diet did not differ significantly in the total number of neurons in the hippocampus. However, the n-3 deficiency leads to a reduction in the cell body size of all neurons in the hippocampus. The authors observed a slight non-significant increase in the volume of CA1 layers in the $n-3$ deficient groups compared to $n-3$ supplemented groups. This suggested that DHA deficiency caused a significant reduction in the size of CA1 neurons without significantly altering other parameters including density and total neurons. The cortical and hippocampal pyramidal cells are among the largest neurons in the nervous system; their dendritic fields are among the most highly arborized; their projection distances are lengthy; and their metabolic requirements are among the highest ones [22]. The metabolism changes with age and an increase in the oxidative stress results in a lower concentration of $n-3 F A$ in the nervous system. A recent investigation has shown that diets rich in PUFA had a protective action in mild $A D$ inversely to diets rich in saturated and trans fat. The low plasmatic concentration of n-3 FA, including DHA, is an indicator of the risk of cognitive deficit and other kinds of dementia [7].

In our present study, the level of p53 protein was used to reveal the distribution of apoptotic neurons and apoptotic glial cells. p53 is a transcription factor and a regulatory protein involved in cell cycle control and apoptosis. DNA damage and other stress signals may trigger the increase in p53 protein, which has three major functions: growth arrest, DNA repair and/ or induction of apoptotic cell death [4]. Accumulation of DNA damage with aging was reported by some scientists in the early 1970s [17]. As a cellular gatekeeper, one of the roles of p53 is to monitor cellular stress and to induce apoptosis as necessary. In tissues where stressors generate severe and irrevocable damage, p53 can initiate apoptosis, thereby eliminating damaged cells [4]. In our study, the number of apoptotic cells increased significantly in the cerebral cortex and in the CA1 hippocampal area in the control group. This suggests that $n-3$ diet helped to decrease the number of apoptotic cells in experimental rats. PUFA depletion in the membrane and, consequently, cell injury might result from excessive ROS generation or an impaired antioxidant defence system. ROS may affect membrane PUFA content and result in lipid peroxidation, which leads to apoptosis. The central nervous system is more sensitive to ROS exposure and lipid peroxidation than other body compartments and organs. Some publications show an anti-apoptotic, beneficial effect of n-3 PUFA in the hippocampus of diabetic rats [11] and cerebral ischemia [5] additionally in prefrontal cortex in MK-801-induced neurotoxicity [20]. Boudrault et al. [8] have suggested that there are several different pathways of neuroprotection. First, they showed that neuroprotectin D1 (NPD1, oxidized derivative of DHA) reduces cell apoptosis and DHA-treated cells. They also suggest that NPD1 and DHA-treated cells have higher gene expression levels of antiapoptotic proteins of the Bcl-2 family. Furthermore, a study by Akbar et al. [2] demonstrated that DHA inhibited caspase-3 activity. Finally, the brain derived neurotrophic factor BDNF has been associated with increased cell survival. Notably, the upregulation of BDNF has been suggested as a potential mechanism of action of $n-3$ PUFA in a rat model of several diseases [8].

\section{Conclusions}

In conclusion, the present data demonstrate that fish oil supplemented diet significantly decreased content of arachidonic acid in the cerebral cortex and hippocampus. Furthermore DHA content in the cerebral cortex substantially increased in rats fed a diet enriched with fish oil. While the main effect was most likely due to the increased PUFA concentration in fish oil diet, the difference in saturated and mono-saturated FA between the two diets cannot be entirely dismissed. In the hippocampus, there were no differences between the two dietary groups. The number of apoptotic cells was clearly higher in 
the cerebral cortex and CA1 area of the hippocampus in the control group rats. This suggests a positive effect of fish oil supplemented diet (FOD) in those parts of brain in animals of the experimental group. We also observed a higher density of pyramidal cells in the cerebral cortex in rats fed FOD. The neuroprotective effect of FOD containing DHA and EPA might be related to its reduced content of saturated and monounsaturated FA in the diet. These results suggest that dietary intake of fish oil is crucial for the good brain functioning and may be helpful in prevention of age-related pathological impairments.

\section{Acknowledgements}

This work was supported by grant no. N N312 337939 from the Ministry of Science and Higher Education. We would like to thank the Mazovian Oncology Hospital Staff for professional assistance in the immunohistological section and technical support.

\section{References}

1. Ahmad A, Murthy M, Greiner RS, Moriguchi T, Salem N. A decrease in cell size accompanies a loss of docosahexaenoate in the rat hippocampus. Nutri Neuroscie 2002; 5: 103-113.

2. Akbar M, Calderon F, Wen Z, Kim HY. Docosahexaenoic acid: a positive modulator of Akt signaling in neuronal survival. Proc Natl Acad Sci USA 2005; 102: 10858-10863.

3. Babenko AN, Semenova AY. Effects of long-term oil-enriched diet on the sphingolipid metabolism in brain of old rats. Exp Gerontol 2010; 45: 375-380.

4. Bai L, Zhu GW. p53: Structure, function and therapeutic applications. J Cancer Molecu 2006; 2: 141-153.

5. Bas O, Songur A, Sahin O, Mollaoglu H, Ozen A O, Yaman M, Eser O, Fidan $\mathrm{H}$, Yagmurca M. The protective effect of fish $n$-3 fatty acids on cerebral ischemia in rat hippocampus. Neurochemistry 2007; 50: 548-554.

6. Borras D, Ferrer I, Pumarola M. Age-related changes in the brain of the dog. Vet Pathol 1999; 36: 202-211.

7. Borsonelo EC, Galduroz JCF. The role of polyunsaturated fatty acids (PUFAs) in development, aging and substance abuse disorders: Review and propositions. Prostaglandins Leucot Essent Fatty Acids 2008; 78: 237-245.

8. Boudrault C, Bazinet PR, Ma DL. Experimental models and mechanisms underlying the protective effects of $n-3$ polyunsaturated fatty acids in Alzheimer's disease. J Nutr Biochem 2009; 20: 1-10.

9. Cao D, Kevala K, Kim J, Moon HS, Jun BS, Lovinger D, Kim HY. Docosahexaenoic acid promotes hippocampal neuronal development and synaptic function. J Neurochem 2009; 111: 510-521.

10. Carrie I, Clement M, Javel D, Frances H, Bourre JM. Specific phospholipid fatty acid composition of brain regions in mice: effects of n-3 polyunsaturated fatty acid deficiency and phospholipid supplementation. J Lipid Res 2000; 41: 465-472.
11. Cosar M, Songur A, Sahin O, Uz E, Yilmaz R, Yagmurca M, Ozen OA. The neuroprotective effect of fish $n-3$ fatty acids in the hippocampus of diabetic rats. Nutr Neurosci 2008; 11: 161-167.

12. Folch J, Lees M, Sloane Stanley GH. A simple method for the isolation and purification od total lipides from animal tissues. J Biol Chem 1957; 226: 497-509.

13. Guo MF, Yu JZ, Ma CG. Mechanisms related to neuron injury and death in cerebral hypoxic ischaemia. Folia Neuropathol 2011; 49 : 79-87.

14. Harbeby E, Jouin M, Alessandri JM, Lallemand MS, Linard A, Lavialle M, Huertas A, Cunnane SC, Guesnet P. n-3 PUFA status affects expression of genes involved in neuroenergetics differently in the fronto-parietal cortex compared to the CA1 area of the hippocampus: effect of rest and neuronal activation in the rat. Prostaglandins Leukot Essent Fatty Acids 2012; 86: 211-220.

15. Igarashi M, Gao F, Kim HW, Ma K, Bell JM, Rapoport SI. Dietary n-6 PUFA deprivation for 15 weeks reduces arachidonic acid concentrations while increasing n-3 PUFA concentrations in organs of post-weaning male rats. Biochim Biophys Acta 2009; 1791: 132-139.

16. Ledesma DM, Martin GM, Dotti CG. Canine and feline intracranial meningiomas: An updated review. Prog Lipid Res 2012; 51: 23-35.

17. Mandavilli BS, Rao KS. Accumulation of DNA damage in Aging neurons occurs through a mechanism other than apoptosis. J Neurochem 1996; 67: 1559-1565.

18. Miller D, O'Callaghan J. Aging, stress and the hippocampus. Aging Res Rev 2005; 4: 123-140.

19. Morrison JH, Hof PR. Life and death of neurons in the aging brain. Science 1997; 278: 412-419.

20. Ozyurt B, Sarsilmaz M, Akpolat N, Ozyurt H, Akyol O, Herken H, Kus I. The protective effects of omega-3 fatty acids against MK-801-induced neurotoxicity in prefontal cortex of rat. Neurochem Int 2007; 50: 196-202.

21. Płotek W. Starzenie się ośrodkowego układu nerwowego i anestezja. Anestozjologia i Ratownictwo 2008; 1: 35-43.

22. Rogers J, Zornetzer FS, Bloom EF, Mervis ER. Senescent microstructural changes in rat cerebellum. Brain Res 1984; 292: 23-32.

23. de Souza AS, Pacheco Lda C, Castro Pda S, Hokoç JN, Rocha MS, do Carmo MG. Brain Fatty acid profiles and spatial learning in malnourished rats: effect of nutritional intervention. Nutr Neurosci 2008; 11: 119-127.

25. Sherwood ChC, Gordon AD, Allen JS, Phillips AK, Erwin JM, Hof PR, Hopkins WD. Aging of the cerebral cortex differs between humans and chimpanzees. Proc Natl Acad Sci USA 2011; 108: 13029-13034.

25. Small AS, Chawla KM, Buonocore M, Rapp PR, Barnes AC. Imaging correlates of brain function in monkeys and rats isolates a hippocampal subregion differentially vulnerable to aging. Proc Natl Acad Sci USA 2004; 101: 7181-7186.

26. Soriguer F J, Tinahones F J, Monzon A, Pareja A, Rojo-Martinez G, Moreno F, Esteva I, Gómez-Zumaquero JM. Varying incorporation of fatty acids into phospholipids from muscle, adipose and pancreatic exocrine tissues and thymocytes in adult rats fed with diets rich in different fatty acids. Eur J Epidemiol 2000; 16: 585-594.

27. Yehuda S, Rabinovitz S, Mostofsky DI. Essential fatty acids and the brain: from infancy to aging. Neurobiol Aging 2005; 26: 98-102. 